Proceedings of the 2012 Winter Simulation Conference

C. Laroque, J. Himmelspach, R. Pasupathy, O. Rose, and A. M. Uhrmacher, eds.

\title{
GROUNDED THEORY BASED AGENTS
}

\author{
Arianna Dal Forno \\ Department of Economics \\ "Cognetti de Martiis" \\ University of Torino \\ via Po 53 \\ I-10124 Torino, ITALY
}

\author{
Ugo Merlone \\ Department of Psychology \\ University of Torino \\ via Verdi 10 \\ I-10124 Torino, ITALY
}

\begin{abstract}
In agent based modeling many approaches are used for modeling agents' behavior. They range from relaxing the rationality assumption to considering participants' behavior in experiments. Important suggestions come from qualitative research in particularly from social sciences. We propose an approach to model artificial agents by applying Glaser and Strauss Grounded Theory.

As an example, we ran an experiment with human participants facing an incentive problem. We show how the observed behaviors were coded to ground the behavioral rules of agents. We then compared the results obtained with grounded agents simulation to human participants' performance and to the theoretical optimum obtainable with fully rational agents. This method can generate simulated data with statistical distribution not significantly different from experimental data. This approach can be fruitfully applied to several problems of social interactions in organizations and work groups.
\end{abstract}

\section{INTRODUCTION}

The importance of individual behavior at work is well known in the literature. For instance, Roy (1952) observed different behaviors in response to a managerial incentive designed to increment production in a machine shop. Industrial workers did not react as theory predicts, forcing managers to change the incentive scheme, and consequently, triggering new reactions. For this reason individual behaviors and interactions in the workplace cannot be ignored. More generally, Thompson (2003) devotes a whole chapter to the human variable and states "The human actor is a multidimensional phenomenon subject to the influences of a great many variables. [...] Neither we nor organizations have the data or the calculus to understand organization members in their full complexity, and the requirements of complicated technologies in complicated task environments cannot be met if the full range of human variations comes into play within the organization".

When modeling individual behavior, a common approach is suggested from the normative perspective of individual decision making (Tversky and Kahneman 1986); in this case rational agents are considered. Nevertheless, starting from the seminal contribution by Simon (1945) this assumption needs to be relaxed, and boundedly rational agents should be considered. In this case the goal is more focused to model realistic behaviors and one important source of inspiration comes from the observation of human participants' behavior in experiments (Dal Forno and Merlone 2004; Boero et al. 2010). However, how to translate the observed behaviors into computer code is not so obvious. Some interesting suggestions come from qualitative research methods to analyze and interpret data. In particular, we apply these methods to the data gathered when observing human agents interacting in situations close to those to be modeled. In this paper we illustrate the approach coming from Glaser and Strauss (1967) later developed by Strauss and Corbin (1998). This approach is called Grounded Theory and, according to Strauss (1987), it "is a style of doing qualitative analysis that includes a number of distinct features, such as theoretical sampling, and certain methodological guidelines, such as the making of constant comparisons and the use of a coding 


\section{Dal Forno, and Merlone}

paradigm, to ensure conceptual development and density". The use of Grounded Theory in multi-agent simulations has been proposed by Andrews et al. (2005), but, to the best of our knowledge, an example showing the steps used in the modeling process and a validation analysis (Sargent 1984) is still missing. In this paper we make these aspects more explicit and the whole process more transparent. This way we show how this methodological approach allows us to strengthen the use of experimental data for modeling some classes of behaviors by means of the observation of human participants (Dal Forno and Merlone 2004) giving replicability and methodological soundness. Grounded Theory implies a constant dialogue between inductive and deductive processes, in order to more and more precisely define the theory of the phenomenon under study. As Giorgino (1999) observes, Glaser and Strauss were rather vague-at least until 1987-on giving a concrete procedure to build Grounded Theory. Turner (1981) was the first author to suggest that the analysis might be the process highlighting the qualitative properties of the examined phenomenon towards a better comprehension. In this direction, Strauss (1987) provided a guide to Grounded Theory, stressing the fact that there are not fixed rules but rather rough indications, and that the suggested procedures have to be adapted and even modified to the context. Since then, several authors published their contributions towards the definition of a theoretical and formal construction procedure. Yet, the difficulty to make the theory building/modeling steps explicit is far from being definitely solved. In order to show how Grounded Theory can be effectively used to build artificial agents, we consider a problem which can be analyzed both formally and with human participants experiments. This problem is modeled as a supervised work group where incentives must be determined in order to maximize productivity. Since we make both the empirical data and the code available upon request, our results are replicable. The experiment instructions and the spreadsheet we used to code participants' behavior are also available upon request. Also, other scientists can use these data to build alternative theories on agents' behavior.

The structure of the paper is the following. In Section 2 we describe the Grounded Theory approach; Section 3 provides an exemplification of this approach on a model of interaction we have studied. In Section 4 we present the experiment we conducted with human participants, and in Section 5 we suggest how to apply the Grounded Theory to model agents' behavior. Section 6 is devoted to the analysis of the data we obtained and Section 7 to conclusion.

\section{GROUNDED THEORY}

According to Strauss and Corbin (1998), Grounded Theory is a theory that is derived from data systematically gathered and analyzed through the research process. Grounded Theory does not test hypotheses, rather it provides a method that enables researchers to analyze and interpret their data in order to have a theory emerging from this analysis process. The basic idea of Grounded Theory is to read a textual database several times and find interrelations between some aspects that emerge during the process. Starting with a research situation, where the researcher's goal is to find what is happening or how the players are managing their roles, the observed behaviors are written. Then, by the analysis and the constant comparison of the data, some of the observed phenomena are labeled; in the terminology of Strauss and Corbin (1998) they become concepts. As concepts begin to accumulate they are grouped under more explanatory terms: categories. By this process, as a theory emerges it is continuously compared to the data. The process continues in order to saturate all the categories, that is, when no new information seems to emerge by coding. This is called theoretical saturation (Strauss and Corbin 1998). By axial coding categories are related to their subcategories in order to develop them according to their properties and dimensions. Furthermore, the theory is integrated and refined by selective coding. At this point a theory grounded on the data has emerged. Finally, it is necessary to test this theory and relate it to other existing theories.

Although Grounded Theory is mainly used in social sciences, some applications can be recently found in other fields; for example, Jones and Alony (2011) apply it to information systems and Graham and Thomas (2008) to knowledge management. Here, as mentioned in the introduction, we use Grounded Theory to model participants' behavior and code it in agent based simulations. 


\section{Dal Forno, and Merlone}

\section{AN APPLICATION TO AN OPTIMAL INCENTIVE PROBLEM}

In order to illustrate how Grounded Theory can be used to model artificial agents' behavior it may be useful to apply it to an example studied in the literature (Dal Forno and Merlone 2004; Dal Forno and Merlone 2007; Dal Forno and Merlone 2010a; Dal Forno and Merlone 2010b). To this purpose we consider a model of supervised work group in which a manager and two operatives cooperate. In this model the manager acts as a principal while the two operatives act as agents; for a first survey of the principal-agent literature when several agents are considered, the reader can refer to Macho-Stadler and Pérez-Castrillo (1997). This literature assumes that "contracting parties are rational individuals who aim to achieve the highest possible payoff" (Bolton and Dewatripont 2005, p.5). By contrast, with our approach, we are interested in observing and modeling actual behavior of human participants to improve realism in simulation.

In the model of interaction we consider, agent $i$ has a capacity $\bar{c}_{i}$ to be allocated between effort $l_{i}$, provided with his partner, and effort $u_{i}$, provided with his manager. The joint production function for agents 1 and 2 is $\left(u_{1}+u_{2}\right)^{\alpha}\left(l_{1}+l_{2}\right)^{\beta}$, where $0<\alpha<1$ and $0<\beta<1$ are, respectively, the output elasticity with respect to the joint effort with the manager and with the partner. Figure 1 illustrates the allocation of the efforts exerted by the two considered agents.

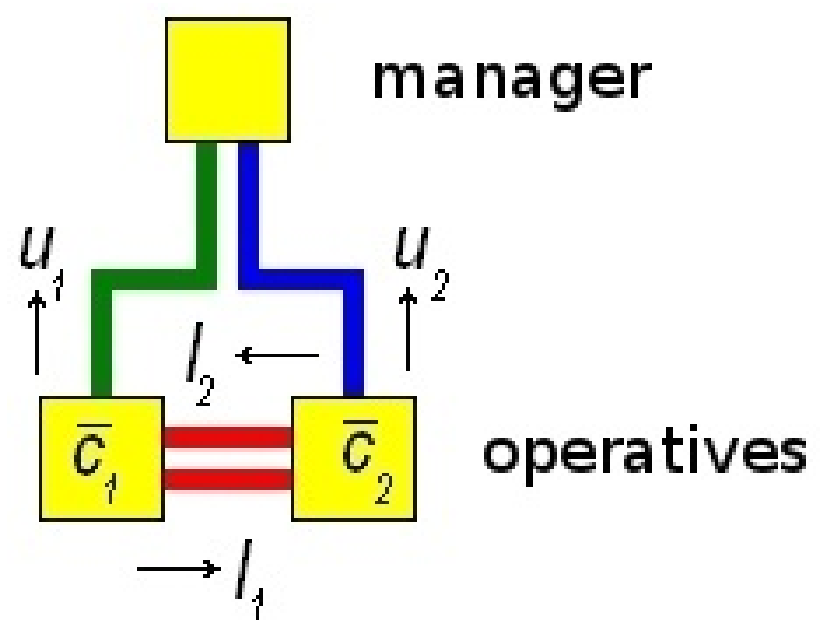

Figure 1: Interaction in a model of supervised work group. Arrows indicate the agents' effort allocation.

The agents have to decide both how much effort to exert, and how to partition it in the two complementary tasks given the incentives provided by the manager. It is immediate to observe that the two tasks are not additive; for a discussion the reader may refer to Spector (2003). Furthermore, agent $i$ can observe the level effort $l_{-i}$ his partner provides with him, but not the one which is provided with the manager. We adopt the notation commonly used in the Game Theory literature (see for example Fudenberg and Tirole (1991)); $-i$ indicates the partner of agent $i$. Conversely, the manager can only observe the joint output and the effort $u_{i}$ each agent provides with her. The manager's profit is the supervised work group production minus the incentives she pays to her operatives. Finally, agents' retribution consists of a fixed wage $w \geq 0$ plus the performance-contingent reward set by the manager. The performance-contingent reward is a linear incentive $b_{g}$ proportional to the joint output of the work group and a linear incentive $b_{i}$ on the effort each agent exerts with the manager. As in Dal Forno and Merlone (2010b) we assume that the operatives' capacity is given and unused capacity cannot be used for other tasks; therefore, operatives' cost function is

$$
c_{i}\left(u_{i}, l_{i}\right)=\left\{\begin{array}{rll}
0 & \text { if } \quad u_{i}+l_{i} \leq \bar{c}_{i} \\
+\infty & \text { if } \quad u_{i}+l_{i}>\bar{c}_{i}
\end{array} \quad i=1,2 .\right.
$$




\section{Dal Forno, and Merlone}

Therefore, the problem can be formalized as a bilevel programming problem:

$$
\max _{b_{g}, b_{1}, b_{2}}\left(1-2 b_{g}\right)\left(u_{1}+u_{2}\right)^{\alpha}\left(l_{1}+l_{2}\right)^{\beta}-b_{1} u_{1}-b_{2} u_{2}
$$

such that, given $b_{g}, b_{1}, b_{2}$ operatives solve

$$
\begin{aligned}
& \max _{u_{1}, l_{1}} w+b_{g}\left(u_{1}+u_{2}\right)^{\alpha}\left(l_{1}+l_{2}\right)^{\beta}+b_{1} u_{1}-c_{1}\left(u_{1}, l_{1}\right) \\
& \max _{u_{2}, l_{2}} w+b_{g}\left(u_{1}+u_{2}\right)^{\alpha}\left(l_{1}+l_{2}\right)^{\beta}+b_{2} u_{2}-c_{2}\left(u_{2}, l_{2}\right) .
\end{aligned}
$$

As proved in Dal Forno and Merlone (2010b), when considering fully rational agents the optimal incentive scheme is

$$
\left\{\begin{array}{l}
b_{g}=\varepsilon>0 \\
b_{1}=0 \\
b_{2}=0
\end{array}\right.
$$

where $\varepsilon$ is a positive number, as small as possible. In this case the optimal effort allocation is

$$
\left(u_{i}, l_{i}\right)=\left(\frac{\alpha}{\alpha+\beta} \bar{c}_{i}, \frac{\beta}{\alpha+\beta} \bar{c}_{i}\right) \quad i=1,2
$$

and the net production is

$$
\pi_{N}=\left(1-2 b_{g}\right)\left(\frac{\alpha}{\alpha+\beta}\left(\bar{c}_{1}+\bar{c}_{2}\right)\right)^{\alpha}\left(\frac{\beta}{\alpha+\beta}\left(\bar{c}_{1}+\bar{c}_{2}\right)\right)^{\beta} .
$$

\section{THE EXPERIMENTAL DESIGN}

We performed an experiment with human participants facing the formal problem presented in the previous section. The purpose of the experiment was to observe the behavior of participants in the situations we considered in our model. We collected the data from 54 undergraduates at the University of Torino (Biella Campus). Participants were told how long the experiment would have taken (time varied slightly among the groups but was around fifteen minutes) and that some extra time would be required for writing a report explaining motivations behind their choices. In this way each quantitative data was supported by a qualitative description.

Detailed written instructions for the experiment were given to the participants one week in advance, so that they could discuss about it and increase their understanding of the game.

Motivating participants in experiments is a well-known problem in the experimental economics literature. We encouraged participation in our students giving them up to 1 mark in addition to whatever their grade would be in the final exam of the Math class (the maximum available grade is 30/30 and pass grade is 18/30). Participants were also told that their actual incentive depended on their performance, that is the total aggregate profit over the whole experiment (incentive $=$ ranked performance normalized in $[0,1])$. Economists and psychologists do not usually agree that monetary incentives improve performance in laboratory experiments (Gneezy and Rustichini 2000). For example, Frey and Oberholzer-Gee (1997) argue that monetary rewards may have a negative effect on intrinsic motivation. As the final exam allowed the students to obtain up to $24 / 30$, the remaining credits were the result of different optional activities during the semester. This way the participants in these activities were only those well motivated to obtain extra credits.

Since in particular, we were interested in observing a situation where the operatives are different in terms of capacity, we considered three roles:

- manager, 


\section{Dal Forno, and Merlone}

- high-capacity operative, and

- low-capacity operative.

The experiment was run in nine weekly sessions where two groups interacted separately; each participant was allowed to take part only in a single session. One week before the first session, participants were given the instructions for the experiment and a short explanatory discussion took place. For each session we asked the participants to volunteer one week in advance. The day the experiment took place, roles were randomly attributed and, while participants were aware of their own role, they were not aware of the others' one. Furthermore, no communication was allowed during the experiment in order to avoid cheap talk issues. In particular, capacity and effort allocation remained private. This approach allowed the participants to communicate across sessions. Yet, since roles were randomly attributed and the interaction was the result of incentives and effort dynamics, we do not expect this kind of communication to affect participants' behavior too much. Finally, in each session of the experiment each participant was given further instructions adapted to the role he/she was playing. These instructions are not reported for brevity's sake.

Each session consisted of five periods in which actions took place. Each period was divided into three steps, where the experimenter was in charge of collecting and transmitting all the relevant information to the participants:

1. incentives-manager plans the individual incentives $b_{1}$ and $b_{2}$ (privately communicated to each agent) and publicly communicates the collective incentive $b_{g}$;

2. efforts-once both personal and collective incentives have been learnt, operatives allocate their capacity between the effort $u_{i}$ (privately communicated to the manager) and $l_{i}$ (privately communicated to the colleague);

3. production and payoffs-the experimenter calculates and publicly communicates the total production and, accordingly to the incentives, payments (privately communicated to the agents) and net result (privately communicated to the manager).

In each step, for each of the five periods of the session, written motivations of participants' decision were required. To this purpose group members received a form to be filled during the experiment. The motivations provided by participants gave different kinds of information that enabled us to complement the simple observation of their behavior in terms of given incentives and provided efforts. In particular, the motivations our participants provided, allowed the modeling of artificial agents' behavior to be grounded on the rationale behind their choices. Since we were interested in the performance of the groups as a whole as a result of the dynamics of members' choices, we considered only the net production of each of the 18 experimental groups. The cumulated net productions are reported in Table 1.

\section{APPLYING GROUNDED THEORY TO THE MODELING PROCESS}

The approach we used in categorizing and labeling the different behaviors is one of the most used methods in qualitative research and is explained in the following paragraphs; for further details the reader may consult Glaser and Strauss (1967), and Strauss and Corbin (1998).

Since in the analysis of the data groups were behaving as whole units where both managers and their operatives were interacting and adjusting each other, it was difficult to model roles separately. As a matter of fact, all participants' strategies seemed to be the result of both their initial assumptions on the game and the other participants' actions. A different approach would have been studying just one role at the time, for example having one human participant interacting with artificial coworkers. This way, while it would have been easier to understand a single role, we would have lost the joint construction of mutual interaction between human participants. 


\section{Dal Forno, and Merlone}

Table 1: Cumulated net production at the end of interactions of experimental groups.

\begin{tabular}{c|c} 
Group & Cumulated net production \\
\hline 1 & 25.6538 \\
2 & 23.3699 \\
3 & 26.9796 \\
4 & 24.5496 \\
5 & 27.4600 \\
6 & 15.2775 \\
7 & 27.6502 \\
8 & 12.1146 \\
9 & 19.4991 \\
10 & 26.1298 \\
11 & 28.5813 \\
12 & 18.0891 \\
13 & 21.8695 \\
14 & 30.8273 \\
15 & 26.8022 \\
16 & 26.9981 \\
17 & 28.5837 \\
18 & 24.2502
\end{tabular}

Although several software tools can be used to analyze the data we collected, in this study we organized our data using a spreadsheet. In this way the choices we made in the analysis process are more transparent. The original material was organized as an ordered set of debriefing questionnaires partitioned according to roles, i.e., manager, high-capacity operative and low-capacity operative. Through a process of joint analysis of given motivations (qualitative data) and actual agent actions (quantitative data) we labeled each agent's behavior. The first important point was the distinction of actions performed on the first turn-mainly based on participants' expectations on the game-from actions performed in the following turns-as a reaction to previous interactions. By writing the different observed behaviors we could develop several concepts that, as they accumulated, formed different categories of behavior. Finally, when categories were saturated we used axial coding in order to relate and fit the categories. Through this process we could categorize several components of behavior both for operatives and managers; they have been coded using a spreadsheet. A magnified detail is provided in Figure 2. There, each agent's motivation (in italics) is reported in a cell. Cells in bold type denote concepts, subcategories and categories which emerged from categorizing agents' motivations. In particular, as it concerns the operative role, the categories of behavior we could identify are reported in Table 2 . In this table $c_{i}^{\tau} \leq \bar{c}_{i}$ is the capacity agent $i$ devolves to efforts at time $\tau$, while $u_{i}^{\tau}$ and $l_{i}^{\tau}$ are, respectively, agent $i$ 's effort with manager and partner at time $\tau$. Function $r$ is any convenient behavioral rule used to determine the effort to be exerted.

As it concerns managers, the categories that emerged are reported in Table 3. In this table $\pi_{N}^{\tau}=$ $\left(u_{1}^{\tau}+u_{2}^{\tau}\right)^{\alpha}\left(l_{1}^{\tau}+l_{2}^{\tau}\right)^{\beta}-\left(1-b_{1}^{\tau}-b_{2}^{\tau}-2 b_{g}^{\tau}\right)$ is the net production at time $\tau$, and $r_{1}, r_{2}, r_{g}$ are the observed behavioral rules used to assign respectively the two individual incentives and the one for the group.

By combining some of them we modeled the classes of behavior described in the following.

- manager $M 1$ (individual punisher): at the first turn she gives both operatives a low collective incentive and slightly higher individual incentives. At the next turns, if the net production has increased, then she increases the individual incentive of the operative who exerted the higher effort with her, otherwise (i.e., if the net production does not increase) she decreases the individual incentive of the lower effort operative. 
Dal Forno, and Merlone

\begin{tabular}{|c|c|c|c|c|c|c|}
\hline \multirow{3}{*}{2} & A & \multicolumn{5}{|c|}{ Allocation proportional to incentives } \\
\hline & & \multirow[b]{2}{*}{$\begin{array}{l}\text { Allocate proportionally to } \\
\text { incentives }\end{array}$} & \multirow[b]{2}{*}{$\begin{array}{l}\text { If incentives are equal, } \\
\text { then the effort is equally } \\
\text { allocated between the } \\
\text { two tasks }\end{array}$} & \multirow[b]{2}{*}{$\begin{array}{l}\text { If individual } \\
\text { incentive is higher, } \\
\text { then only work with } \\
\text { manager }\end{array}$} & \multicolumn{2}{|c|}{ Only work with manager } \\
\hline & & & & & $\begin{array}{l}\text { If only individual } \\
\text { incentive, then only } \\
\text { work with manager }\end{array}$ & $\begin{array}{l}\text { If only individual } \\
\text { incentive, then only } \\
\text { work with manager }\end{array}$ \\
\hline 4 & A_H_3 & & & $\begin{array}{l}\text { If individual incentive } \\
\text { increases, I increase } \\
\text { effort with manager } \\
\text { because the payment } \\
\text { will be higher }\end{array}$ & & \\
\hline 5 & B_H_2 & & $\begin{array}{l}\text { Equally shared in } \\
\text { consideration to partner } \\
\text { effort and incentives }\end{array}$ & & & \\
\hline 6 & B_L_3 & & & & & $\begin{array}{l}\text { Since only my } \\
\text { individual incentive } \\
\text { increases, I increase } \\
\text { the effort with manager } \\
\text { as much as possible }\end{array}$ \\
\hline 7 & C_L_3 & & & & $\begin{array}{l}\text { Because payment } \\
\text { decreases while } \\
\text { production is } \\
\text { unchanged, and } \\
\text { individual incentive } \\
\text { decreases }\end{array}$ & \\
\hline 8 & C_L_4 & $\begin{array}{l}\text { Since individual incentive is twice } \\
\text { as much as the collective one II } \\
\text { exert the effort where the incentive } \\
\text { is greater and gives a higher profit; } \\
\text { at the same time, since production } \\
\text { is in the form of product I try to } \\
\text { avoid null effort with the partner }\end{array}$ & & & & \\
\hline
\end{tabular}

Figure 2: Detail of the spreadsheet for operatives' behavior categorization. Behaviors are in cells as emerged by the analysis of the qualitative data provided by participants to the experiment. Cells in bold type denote concepts (row 3), subcategories (row 2), and categories (row 1).

- manager $M 2$ (group punisher): at the first turn she gives both operatives a low collective incentive and slightly higher individual incentives. At the next turns, if the net production has increased, then she increases the individual incentive of the operative who exerted the higher effort with her, otherwise (i.e., if the net production does not increase) she decreases both individual incentives.

- operative $O 1$ (partitioner): at each turn he uses all of his capacity partitioning it proportionally to the individual and collective incentives.

- operative $O 2$ (increasingly partitioner): he increases the used capacity over time and partitions it proportionally to the individual and collective incentives.

- operative $O 3$ (incentive averager): he uses his capacity proportionally to the ratio of incentives just received with the average of the incentives so far obtained; the used capacity is partitioned proportionally to the individual and collective incentives.

Table 2: Examples of operatives' behaviors emerging from the data analysis and their formalization.

\begin{tabular}{|c|c|}
\hline Behavior description & Formal modeling \\
\hline use the whole capacity & $c_{i}^{\tau}=\bar{c}_{i}$ \\
\hline increase over time the capacity assigned to efforts & $c_{i}^{\tau}=\bar{c}_{i}\left(1-\frac{1}{1+\tau}\right)$ \\
\hline & $u_{i}^{\tau}=\frac{b_{i}^{\tau}}{b_{i}^{\tau}+b_{g}^{\tau}} c_{i}^{\tau}$ \\
\hline partition efforts according to received incentives & $l_{i}^{\tau}=\frac{b_{g}^{\tau}}{b_{i}^{\tau}+b_{g}^{\tau}} c_{i}^{\tau}$ \\
\hline diminishing efforts when incentives dropped & $\left\{\begin{array}{lll}u_{i}^{\tau}<u_{i}^{\tau-1} & \text { if } & b_{i}^{\tau}<b_{i}^{\tau-1} \\
l^{\tau}<l^{\tau-1} & \text { if } & h^{\tau}<h^{\tau-1}\end{array}\right.$ \\
\hline react to the effort provided by partner & $l_{i}^{\tau}=r\left(l_{i}^{\tau-1}, l_{-i}^{\tau-1}\right)$ \\
\hline
\end{tabular}




\section{Dal Forno, and Merlone}

Table 3: Examples of managers' behaviors emerging from the data analysis and their formalization.

\begin{tabular}{|c|c|}
\hline Behavior description & Formal modelization \\
\hline incentivize mainly individual efforts & $b_{g}^{\tau} \leq b_{1}^{\tau}, b_{2}^{\tau}$ \\
\hline incentivize mainly collective production & $b_{g}^{\tau} \geq b_{1}^{\tau}, b_{2}^{\tau}$ \\
\hline reward who provides higher effort with the manager & $b_{i}^{\tau}=\left\{\begin{array}{lll}b_{i}^{\tau-1}+\delta & \text { if } & u_{i}^{\tau-1}>u_{-i}^{\tau-1} \\
b_{i}^{\tau-1} & \text { if } & u_{i}^{\tau-1} \leq u_{-i}^{\tau-1}\end{array}\right.$ \\
\hline punish who provides the lower effort with the manager & $\begin{array}{l}b_{i}^{\tau}=\left\{\begin{array}{lll}b_{i}^{\tau-1} & \text { if } & u_{i}^{\tau-1}>u_{-i}^{\tau-1} \\
b_{i}^{\tau-1}-\delta & \text { if } \quad u_{i}^{\tau-1} \leq u_{-i}^{\tau-1}\end{array}\right. \\
\left(b^{\tau-1}=r_{1}\left(\pi_{\nu}^{\tau-1}, \pi_{\nu}^{\tau-2}\right)\right.\end{array}$ \\
\hline adjust incentives according to the trend o & $\left\{\begin{array}{l}b_{2}^{\tau-1}=r_{2}\left(\pi_{N}^{\tau-1}, \pi_{N}^{\tau-2}\right) \\
b_{g}^{\tau-1}=r_{g}\left(\pi_{N}^{\tau-1}, \pi_{N}^{\tau-2}\right)\end{array}\right.$ \\
\hline
\end{tabular}

- operative $\mathrm{O} 4$ (group effort limiter): at each turn he uses all of his capacity partitioning it proportionally to the individual and collective incentives, but limiting his effort with the partner to the one he observed the previous turn.

These classes are grounded on the data we collected and analyzed, therefore we do not introduce any exogenous factor in the artificial model. Obviously, it is possible to model other classes considering the available data.

\section{DATA ANALYSIS}

To be consistent with the human participants' experiment, we ran the simulations for five iterations as in the human experiment session; then we considered the cumulated net production at the end of the fifth iteration. In the simulations we used the same parameter values as given to the human participants and reported in Table 4.

Table 4: Parameters used in the experiments: $\alpha, \beta$ are output elasticities; $\bar{c}_{1}, \bar{c}_{2}$ are operatives' capacities; $w$ is the fixed wage.

$$
\begin{aligned}
& \alpha=.7 \\
& \beta=.3 \\
& \bar{c}_{1}=10 \\
& \bar{c}_{2}=2 \\
& w=2
\end{aligned}
$$

With these parameter values, and assuming the groups incentive be $b_{g}=\varepsilon=.01$, the fully rational group's net production $\pi_{N}$ is given by formula (1). Thus the cumulated net production over five periods is $5 \pi_{N} \approx 31.9215$. As expected, this result is larger than any value of Table 1 , confirming that the human subjects did not behave as the theory predicts.

The cumulated net productions obtained with the grounded agents are reported in Tables 5 and 6, where operatives in the rows have high capacity and operatives in the columns have low capacity. Again, the cumulated net production $\left(5 \pi_{N} \approx 31.9215\right)$ of the fully rational group is larger and outside the range of the distribution obtained with artificial agents. Furthermore, we observe that, with both kinds of manager we modeled-individual punisher (M1) and group punisher (M2)-a work group composed by two group effort limiter operatives leads to null production. Actually, in one of the human groups production dropped to zero in the last interaction. However, all the other values of the cumulated production are in the range $[12.1146,30.8273]$ of the results obtained with human participants.

As we could not assume normality for the two distributions, in order to compare human participants' to grounded agents' results, we used the Kolmogorov-Smirnov test. We could not reject the null hypothesis 


\section{Dal Forno, and Merlone}

Table 5: Cumulated net production over five periods for work groups supervised by an individual punisher manager. The high-capacity operative's behaviors are listed in the first row, and those of low-capacity one in the first column.

\begin{tabular}{l|llll}
$\begin{array}{l}\text { Individual } \\
\text { punisher }(M 1)\end{array}$ & $\begin{array}{l}\text { partitioner } \\
(O 1)\end{array}$ & $\begin{array}{l}\text { increasingly } \\
\text { partitioner }(O 2)\end{array}$ & $\begin{array}{l}\text { incentive } \\
\text { averager }(O 3)\end{array}$ & $\begin{array}{l}\text { group effort } \\
\text { limiter }(O 4)\end{array}$ \\
\hline $\begin{array}{l}\text { partitioner }(O 1) \\
\text { increasingly } \\
\text { partitioner }(O 2)\end{array}$ & 24.4816 & 22.9076 & 24.3570 & 24.4816 \\
$\begin{array}{l}\text { incentive } \\
\text { averager }(O 3) \\
\text { group effort } \\
\text { limiter }(O 4)\end{array}$ & 24.5757 & 16.2225 & 17.5757 & 17.5757 \\
& 20.2975 & 17.8253 & 24.3570 & 24.4816 \\
& & & 20.1553 & 0.0000
\end{tabular}

Table 6: Cumulated net production over five periods for work groups supervised by a group punisher manager. The high-capacity operative's behaviors are listed in the first row, and those of low-capacity one in the first column.

\begin{tabular}{l|llll}
$\begin{array}{l}\text { group } \\
\text { punisher }(M 2)\end{array}$ & $\begin{array}{l}\text { partitioner } \\
(O 1)\end{array}$ & $\begin{array}{l}\text { increasingly } \\
\text { partitioner }(O 2)\end{array}$ & $\begin{array}{l}\text { incentive } \\
\text { averager }(O 3)\end{array}$ & $\begin{array}{l}\text { group effort } \\
\text { limiter }(O 4)\end{array}$ \\
\hline $\begin{array}{l}\text { partitioner }(O 1) \\
\text { increasingly } \\
\text { partitioner }(O 2)\end{array}$ & 24.6561 & 23.0538 & 24.5378 & 24.6561 \\
$\begin{array}{l}\text { incentive } \\
\text { averager }(O 3) \\
\text { group effort }\end{array}$ & 17.5757 & 16.2225 & 17.5757 & 17.5757 \\
limiter $(O 4)$ & 18.8999 & 17.4812 & 24.5378 & 24.6561 \\
\end{tabular}

that the samples were drawn from the same distribution $(p=0.08527)$. This is a confirmation that the classes we modeled are a good approximations of the behavior we observed in the human participants' experiment. In fact, the code we used to obtain the results reported in Tables 5 and 6 emerged from empirical analysis and led to behaviors not significantly different from human participants. Therefore, the approach we suggest when considering Grounded Theory to model artificial agents seems to provide results which, at least in this case, cannot be considered too far from the human behavior we observed.

\section{CONCLUSION}

When behavior plays an important role, artificial agents modeling presents a fundamental question. What kinds of behavior should the artificial agents have in order to obtain realistic results from simulation? We suggest a possible method which can be generalized and applied to any process of modeling actual organizations or social interactions.

The method we propose can be divided in three steps. The first step consists in designing an experiment which proposes the same interaction we want to study. This permits to set up the proper environment for the problem under study. In the second step both quantitative and qualitative data are collected and analyzed. The connection between quantitative and qualitative data is helpful for at least three reasons. Firstly, it permits a control of internal coherence. Secondly, although the naked quantitative figure is someway an abstract data and therefore, can be misinterpreted, the clothing provided by the qualitative data allows the interpretation to be closer to reality. Thirdly, and this is connected to the third step of the 


\section{Dal Forno, and Merlone}

method, the classification of extracted behaviors provides a direct way to code artificial agents' behavior answering the question posed above. This approach permits to embed what Turner (1983) calls a "[...] better understanding of repeated segments of human interactions in an organizational setting" into the modeling of artificial agents.

Introducing some grounded artificial agents in the model of interaction, we could find that the different combinations of agents' behavior in the same work group may lead to a variety of outcomes in terms of production and incentive schemes. The validity of the method relies on the fact that the most of the outcomes of the artificial work groups are very close to the actual group performances we observed during the experiments.

The novelty of this approach lies in filling-at least partially-the gap between normative and descriptive theories of decision making. These two approaches in describing decision making take different perspectives and, according to Tversky and Kahneman (1986), cannot be reconciled. As, in agent based simulation, agents are often decision makers, the two different perspectives are reflected on the modelization process as well. For example, when adopting a normative approach, we obtain a model in which starting from the fully rational agent some assumptions are relaxed. Considering the inevitable tradeoffs for theories of social behavior (Weick 1969), this kind of model combines simplicity and generality at the expense of accuracy. By contrast, starting from a descriptive approach the model is more accurate and less simple and general. When incorporating grounded agents in simulations we obtain a more accurate model which, at the same time, allows a sort of "what if" analysis where simulation can be used to establish constructive sufficiency (Young 1998).

Given our results, we believe that this method provides a more realistic tool that can be used successfully to investigate interaction problems. Not least, it is more grounded to empirical data even in a context where data are usually difficult to collect.

\section{REFERENCES}

Andrews, C., A. I. Baptista, and S. L. W. Patton. 2005. "Grounded theory and multi-agent simulation for a small firm". In Agent-based Simulation: From modeling methodologies to real-world applications, edited by T. Terano, H. Kita, T. Kaneda, K. Arai, and H. Deguchi, 167-181. Tokyo: Springer.

Boero, R., G. Bravo, M. Castellani, and F. Squazzoni. 2010. "Why Bother with What Others Tell You? An Experimental Data-Driven Agent-Based Model". Journal of Artificial Societies and Social Simulation 13 (3): 6.

Bolton, P., and M. Dewatripont. 2005. Contract Theory. Cambridge, MA: MIT Press.

Dal Forno, A., and U. Merlone. 2004. "From Classroom Experiments to Computer Code". Journal of Artificial Societies and Social Simulation 7 (3).

Dal Forno, A., and U. Merlone. 2007. "Incentives in Supervised Teams: An experimental and computational approach". Journal of Social Complexity 3 (1): 37-52.

Dal Forno, A., and U. Merlone. 2010a. "Effort Dynamics in Supervised Work Groups". Journal of Economic Behavior and Organization 75:413-425.

Dal Forno, A., and U. Merlone. 2010b. "Incentives and individual motivation in supervised work groups". European Journal of Operation Research 207:878-885.

Frey, B. S., and F. Oberholzer-Gee. 1997, September. "The Cost of Price Incentives: An Empirical Analysis of Motivation Crowding-Out". The American Economic Review 87 (4): 746-755.

Fudenberg, D., and J. Tirole. 1991. Game Theory. Cambridge, MA: MIT Press.

Giorgino, E. 1999. "La Grounded Theory. Una introduzione". Sociologia e professione 35:68-85.

Glaser, B., and A. L. Strauss. 1967. The Discovery of Grounded Theory: Strategies for Qualitative Research. Hawthorne NY: Aldine de Gruyter.

Gneezy, U., and A. Rustichini. 2000. “Pay enough or don't pay at all”. The Quarterly Journal of Economics 115 (3): 791-810. 


\section{Dal Forno, and Merlone}

Graham, B., and K. Thomas. 2008. "Building Knowledge Developing a Grounded Theory of Knowledge Management for Construction”. The Electronic Journal of Business Research Methods 6 (2): 115-122.

Jones, M., and I. Alony. 2011. "Guiding the Use of Grounded Theory in Doctoral Studies An Example from the Australian Film Industry". International Journal of Doctoral Studies 6:95-114.

Macho-Stadler, I., and D. Pérez-Castrillo. 1997. An Introduction to the Economics of Information. Oxford, UK: Oxford University Press.

Roy, D. 1952, March. "Quota Restriction and Goldbricking in a Machine Shop". The American Journal of Sociology 57 (5): 427-442.

Sargent, R. C. 1984, December. "A Tutorial on Verification and Validation of Simulation Models". In Proceedings of the 1984 Winter Simulation Conference, edited by S. Sheppard, U. Pooch, and D. Pegden, 114-121. Piscataway, New Jersey: Institute of Electrical and Electronics Engineers, Inc.

Simon, H. A. 1945. Administrative behavior. Fourth ed. New York, NY: Free Press.

Spector, P. 2003. Industrial and Organizational Psychology. third ed. New York, NY: John Wiley \& Sons. Strauss, A. 1987. Qualitative analysis for social scientists. Cambridge, UK: Cambridge University Press.

Strauss, A. L., and J. M. Corbin. 1998. Basics of Qualitative Research: Techniques and Procedures for Developing Ground Theory. 2nd ed. Thousand Oaks CA: SAGE Publication, Inc.

Thompson, J. 2003. Organizations in Action. New Brunswick, NJ: Transaction Publisher.

Turner, B. A. 1981. "Some practical aspects of qualitative data analysis: One way of organising the cognitive processes associated with the generation of grounded theory". Quality \& Quantity 15:225247. 10.1007/BF00164639.

Turner, B. A. 1983. "The use of grounded theory for qualitative analysis of organizational behavior". Journal of Management Studies 20 (3): 333-348.

Tversky, A., and D. Kahneman. 1986. "Rational Choice and the Framing of Decisions". The Journal of Business 59 (4): S251-S278.

Weick, K. E. 1969. The social psychology of organizing. Reading, MA: Addison-Wesley.

Young, J. 1998, July 46. "Using computer models to study the complexities of human society". The Chronicle of Higher Education, Section A 4 (46): 17-19.

\section{AUTHOR BIOGRAPHIES}

ARIANNA DAL FORNO holds a degree in Mathematics and a Doctorate in Mathematics applied to Economic Decisions. She has been post-doc visiting at the Department of Economics at Harvard University. She is author of several papers published in international journals as Chaos, Solitons and Fractals, European Journal of Operational Research, Journal of Economic Behavior \& Organization, Nonlinear Dynamic, Psychology and Life Sciences. She is also referee for JASSS and Decisions in Economics and Finance. Her email address is arianna.dalforno@unito.it.

UGO MERLONE (Ph.D. in Applied Mathematics, University of Trieste, Italy) is Associate Professor at the Psychology Department, University of Torino, Italy. His main area of interest is the modeling of human behavior and organizations. On these topics he has published on journals such as European Journal of Operational Research, Physica A, Journal of Economic Behavior \& Organization, Journal of Mathematical Sociology, International Game Theory Review, Organization Science, Journal of Artificial Societies and Social Simulation. His email address is ugo.merlone@unito.it and his web page is http: //web.econ.unito.it/merloneugo/. 